\title{
PARÂMETROS OPERACIONAIS DO PROCESSO DE DIGESTÃO ANAERÓBIA DE RESÍDUOS ALIMENTARES: UMA REVISÃO
}

\section{OPERATIONAL PARAMETERS OF ANAEROBIC DIGESTION PROCESS OF FOOD WASTE: A REVIEW}

\author{
Matheus Vitor Diniz Gueri ${ }^{1}$, Samuel Nelson Melegari de Souza², Osvaldo Kuczman ${ }^{3}$ \\ 1, 2, 3 Universidade Estadual do Oeste do Paraná, Cascavel, Paraná, Brasil-mgueri@hotmail.com, \\ samuel.souza@unioeste.br \& osvaldokuczman@hotmail.com
}

RESUMO

\begin{abstract}
A geração de resíduos alimentares cresce conforme aumenta a demanda por alimentos, sendo atrelada a toda a cadeia de produção alimentar. Isso evidencia que novas técnicas devem ser desenvolvidas para assegurar o manejo e o tratamento adequado desses resíduos. A digestão anaeróbia surge então como uma alternativa promissora para o tratamento desses resíduos, que simultaneamente promove a geração de energia limpa e renovável. Sendo assim, a presente pesquisa teve por objetivo elucidar as principais características sobre os parâmetros operacionais da digestão anaeróbia de resíduos alimentares. Os resultados apresentam os problemas encontrados na digestão anaeróbia bem como suas possíveis soluções, descrevendo as características operacionais envolvidas. Pode-se concluir que, dentre os parâmetros pertinentes à digestão anaeróbia de resíduos alimentares, o teor de nutrientes é o mais significativo, o qual pode ser corrigido com a adição de cosubstratos para que o processo ocorra de maneira mais estável.
\end{abstract}

PALAVRAS-CHAVE: Biogás, Sustentabilidade, Tratamento de Resíduos.

\section{ABSTRACT}

The generation of food wastes grows as the demand for food increases, whose bound to the entire food production chain. This emphasize new techniques must be developed to assure the proper handling and treatment of this organic residues. Anaerobic digestion of food waste then arises as a promising alternative for the treatment of food waste that simultaneously promote the generation of clean and renewable energy. Therefore, the present research aimed to clarify the main characteristics about the operational parameters in anaerobic digestion of food waste. The results shown the problems encountered in anaerobic digestion as well as their possible solutions, describing the operational characteristics involved. It can be concluded that among the parameters pertinent to the anaerobic digestion of food wastes, the nutrient content is the most significant, which can be corrected with the addition of cosubstrates in the mix to improve the process.

KEYWORDS: Biogas, Sustainability, Waste Treatment. 


\section{INTRODUÇÃO}

A geração de resíduos sólidos urbanos (RSU) no Brasil em 2014 foi de aproximadamente 78,6 milhões de toneladas, com um aumento de $2,9 \%$ comparado ao ano de 2013. Desse total, mais que $51 \%$ são representados por material orgânico putrescível (ABRELPE, 2013; ABRELPE, 2014). Naturalmente, nos países em desenvolvimento, a composição do RSU é majoritariamente orgânica, apresentando os resíduos alimentares (RA) como um de seus principais constituintes em virtude do processo de urbanização (SANTOS et al., 2014; XU et al., 2015). Além disso, Santos et al. (2014) afirmam que a taxa de crescimento da geração de resíduos é maior do que o ritmo em que cresce a população.

Os resíduos alimentares (RA) são gerados em grandes quantidades, principalmente nos estabelecimentos do segmento de alimentação, tais como restaurantes comerciais e coletivos, churrascarias, pizzarias, lanchonetes e bares e sua composição varia de acordo com os hábitos alimentares locais. No Brasil, geralmente compõem-se de cereais, carnes, massas, embutidos, ovos, frutos e verduras. Esses são originados das sobras dos alimentos preparados e não consumidos e dos alimentos que são servidos e não consumidos. Tal desperdício é influenciado principalmente pela falta de planejamento do número de refeições, tipicidade do alimento, modo de preparo, ausência de indicadores de qualidade, compras feitas sem critérios, entre outros (ZANDONADI \& MAURICIO, 2012). Além disso, a geração de resíduo alimentar é inerente ao crescimento populacional, pois está relacionada a todas as etapas da cadeia alimentar. Assim, quanto maior a demanda por alimentos maior será a geração destes resíduos (ZHANG et al., 2014).

Tchobanoglous et al. (1993) informam, que devido ao teor orgânico dos resíduos alimentares, que contém aproximadamente entre 70 a $90 \%$ de sólidos voláteis, podem causar problemas ambientais quando são manejados inadequadamente, dado que os produtos da sua degradação são precursores de contaminação hídrica, assoreamento de rios e lagos, proliferação de macro e microvetores, geração de odores e emissão de Gases de Efeito Estufa (GEE). Por outro lado, as características biodegradáveis e a riqueza em nutrientes presentes nesses resíduos, permitem que possam ser reciclados e convertidos em produtos de maior valor agregado, seja na forma de fertilizante orgânico ou energia renovável (YONG et al., 2015; WOON \& LO, 2016).

Os resíduos alimentares podem ser aproveitados por diferentes rotas tecnológicas que promovem a recuperação energética e de nutrientes. Dentre elas, a rota biológica tem se apresentado com maior relevância, principalmente pelo processo de digestão anaeróbia, uma vez que mineraliza a matéria orgânica e simultaneamente produz o biogás contendo metano $\left(\mathrm{CH}_{4}\right)$ que pode ser aproveitado energeticamente e um efluente rico em nitrogênio, fósforo e outros minerais que podem ser utilizados na melhora da fertilidade e da textura dos solos (WOON \& LO, 2016).

A tecnologia de digestão anaeróbia se apresenta como ferramenta fundamental para a gestão dos resíduos sólidos no Brasil, uma vez que permite tratar cerca de $50 \%$ dos resíduos destinados ao aterramento e/ou disposição em vazadouros a céu aberto (SANTOS et al., 2014). Além disso, promove a mitigação das emissões de GEE e, paralelamente, produz energia renovável. Dessa forma, este estudo propôs apresentar uma revisão bibliográfica sobre as principais características envolvidas no processo de digestão anaeróbia sobre resíduos alimentares.

\section{DIGESTÃO ANAERÓBIA}

Consiste em um processo microbiológico natural que proporciona interações enzimáticas e metabólicas sobre compostos orgânicos (biomassa residual), convertendo-os principalmente em matéria estabilizada, metano $\left(\mathrm{CH}_{4}\right)$ e dióxido de carbono $\left(\mathrm{CO}_{2}\right)$. A formação do metano ocorre em ambientes onde o oxigênio, o nitrato e o sulfato não estejam disponíveis como aceptores de elétrons (TCHOBANOGLOUS et al., 1993; CHERNICHARO, 2007; PITK et al., 2013).

A digestão anaeróbia representa um sistema ecologicamente balanceado, onde diversos microrganismos operam simbioticamente em duas etapas (digestão ácida e digestão metanogênica), nas quais agem pelo menos três grupos fisiológicos de microrganismos: bactérias fermentativas (acidogênicas), bactérias sintróficas (acetogênicas), e microrganismos metanogênicos. Cada grupo possui funções específicas, operando em quatro estágios sequenciais: hidrólise, acidogênese, acetogênese e metanogênese (TCHOBANOGLOUS et al., 1993).

$\mathrm{Na}$ hidrólise, as bactérias fermentativas excretam enzimas extracelulares que reduzem os polímeros orgânicos complexos em compostos mais simples, onde as proteínas, os carboidratos e os lipídios são quebrados em aminoácidos, açucares e ácidos graxos, respectivamente, sendo a etapa mais ativa do processo anaeróbio e também responsável pela velocidade global de reação (AMANI et al., 2010). Em seguida, os microrganismos envolvidos na 
acidogênese são responsáveis por metabolizar os produtos solubilizados na hidrólise, formando dióxido de carbono, hidrogênio, ácido propiônico, ácido butírico, ácido acético, ácido lático, ácido valérico e ácido sulfúrico.

Nessa etapa, também agem os microrganismos facultativos, fundamentais para oxidar o substrato orgânico pela via aeróbia e consumir o oxigênio dissolvido, impedindo que esse se torne uma substância tóxica na etapa metanogênica (OLIVEIRA, 2012). Os microrganismos envolvidos na acidogênese se proliferam muito rapidamente, cerca de 30 a 40 vezes mais rápido que os metanogênicos, e podem sobreviver em condições extremas, como pH baixo, altas temperaturas e elevadas cargas orgânicas (AMANI et al., 2010).

$\mathrm{Na}$ fase da acetogênese, os microrganismos sintróficos convertem os compostos intermediários (ácidos graxos e álcoois) em acetato, hidrogênio, formiato e dióxido de carbono, que serão consumidos pelas metanogênicas. A relação sintrófica entre esses microrganismos com os metanogênicos é fundamental para a assegurar uma melhor performance para o processo (AMANI et al., 2010). Por fim, os microrganismos metanogênicos (procariotas estritamente anaeróbios) convertem o acetato e o hidrogênio produzidos nas etapas anteriores em metano e dióxido de carbono (CHERNICHARO, 2007; DEUBLEIN e STEINHAUSER, 2008).

Nesse processo, os microrganismos metanogênicos desenvolvem funções de grande importância, convertendo o carbono orgânico dissolvido em metano (gás insolúvel) e promovendo a manutenção da pressão parcial de hidrogênio, para que as bactérias fermentativas e formadoras de ácido possam vir a consumi-lo e produzir mais produtos solúveis oxidados, que serão substrato das metanogênicas, mantendo assim o equilíbrio da reação de fermentação (CHERNICHARO, 2007; APPELS et al., 2011).

Vale ressaltar que, no processo de digestão anaeróbia, também pode ocorrer a etapa de redução de sulfatos (sulfetogênese), especialmente quando a degradação ocorre em substratos ricos em proteínas. As bactérias redutoras de sulfato (BRS) envolvidas nessa etapa são capazes de utilizar toda a cadeia de ácidos graxos voláteis, hidrogênio, metanol, etanol, glicerol, açúcares, aminoácidos e acetato para o seu metabolismo, tornandoas concorrentes em comum por substrato com as acetogênicas e metanogênicas, perturbando a relação simbiótica que há entre esses microrganismos, levando a uma menor eficiência geral no processo e, consequentemente, menores teores de metano (CHERNICHARO, 2007).

Outro aspecto relevante que pode afetar a simbiose entre os microrganismos envolvidos é referente as taxas de degradação que devem ser iguais em ambos os estágios, para que o processo seja eficiente. Caso contrário, se no primeiro estágio o processo for rápido demais, a concentração de ácidos e de gás carbônico eleva-se e o pH cai abaixo de 7,0. Assim a fermentação ácida ocorre também no segundo estágio. Da mesma forma, se o segundo estágio ocorrer demasiadamente rápido, evidenciando que muitos microrganismos do primeiro estágio estão presentes, a produção de metano diminui e se faz necessário introduzir novos microrganismos do segundo estágio para restabelecer o equilíbrio (DEUBLEIN \& STEINHAUSER, 2008).

A concentração de ácidos graxos voláteis (AGV) é o parâmetro frequentemente utilizado para verificar o equilíbrio ecológico em sistemas anaeróbios. Os AGV são produtos intermediários do processo de digestão anaeróbia, provenientes da degradação de carboidratos, proteínas e lipídeos, e que se caracterizam por serem de baixo peso molecular, como o propionato, o butirato e outros compostos mais reduzidos que o acetato, como os ácidos de cadeias curtas (CHERNICHARO, 2007).

Quando o sistema se apresenta equilibrado, com uma população de bactérias metanogênicas suficiente e em condições favoráveis, os AGV são consumidos logo após serem formados e, portanto, não se acumulam no sistema e o $\mathrm{pH}$ permanece neutro. Por outro lado, com o sistema sob condições de estresse e limitações cinéticas dos microrganismos metanogênicos, os AGV são gerados a uma taxa maior do que são consumidos, acumulando-se no meio e causando uma queda no $\mathrm{pH}$, a qual provoca o azedamento do reator e a atividade dos microrganismos metanogênicos cessa (CHERNICHARO, 2007).

Segundo Van Haandel \& Lettinga (1994), a estequiometria de reações biológicas é mais vantajosa no tratamento anaeróbio em relação ao aeróbio. No tratamento anaeróbio, dispensa-se a necessidade de introdução de um oxidante, cujo processo leva à geração de menos lodo e mais metano, que pode ser utilizado como combustível. Entretanto, a estequiometria intrinsecamente favorável da digestão anaeróbia por si só não a torna uma alternativa adequada para a remoção de material orgânico.

Basicamente, há dois outros fatores importantes: (1) a eficiência de remoção de material orgânico deve ser alta, de modo que haja uma concentração baixa de material orgânico residual no efluente do sistema de tratamento, e (2) a taxa de remoção deve ser alta, de maneira que possa ser efetivada num reator com um curto tempo de permanência, isto é, um reator com o volume pequeno. 
Ambos os fatores estão relacionados à cinética da remoção de material orgânico e às condições operacionais e ambientais no sistema de tratamento de efluentes.

\section{ASPECTOS NATURAIS E DE OPERAÇÃO}

De maneira geral, a eficiência global do processo de digestão anaeróbia e os teores de metano no biogás dependem fundamentalmente das condições ambientais e operacionais nos reatores anaeróbios. Portanto, a qualidade do biogás, na prática, está associada a diversos fatores, tais como: composição do substrato, tamanho da partícula, carga orgânica, $\mathrm{pH}$, alcalinidade, umidade, balanceamento de macro e micronutrientes, temperatura, tempo de retenção hidráulica e frequência de agitação. Da mesma forma, substratos de difícil degradação biológica, principalmente materiais lignocelulósicos, encontram na hidrólise a etapa limitante do processo, visto que as enzimas hidrolíticas não são eficientes na quebra desses materiais (VAN HAANDEL \& LETINGA, 1994; DEUBLEIN e STEINHAUSER, 2008).

A Tabela 1 apresenta os principais parâmetros envolvidos no processo de digestão anaeróbia.

Tabela 1. Parâmetros envolvidos no processo da digestão anaeróbia

\begin{tabular}{|c|c|c|}
\hline Parâmetro & Valor ideal & Observações \\
\hline $\begin{array}{c}\text { Temperatura }\left({ }^{\circ} \mathrm{C}\right) \\
\text { - Mesofílico } \\
\text { - Termofílico }\end{array}$ & $\begin{array}{l}30-40 \\
40-70\end{array}$ & $\begin{array}{l}\text { O limite superior da } \\
\text { mesófila é a temperatura } \\
\text { ideal para uma ótima } \\
\text { produção de biogás. }\end{array}$ \\
\hline $\mathrm{pH}$ & $6,3-7,9$ & $\begin{array}{l}\text { Fora desses níveis os } \\
\text { microrganismos } \\
\text { metanogênicos não se } \\
\text { desenvolvem }\end{array}$ \\
\hline $\begin{array}{l}\text { Alcalinidade } \\
(\mathrm{mg} \mathrm{CaCO} / \mathrm{L})\end{array}$ & 1000 a 5000 & $\begin{array}{c}\text { Neutraliza as variações de } \\
\text { acidez do resíduo }\end{array}$ \\
\hline $\begin{array}{c}\text { Acidez Volátil } \\
\left.\text { (mg CH}{ }_{3} \mathrm{COOH} / \mathrm{L}\right)\end{array}$ & 500 a 2000 & $\begin{array}{l}\text { Concentrações mais altas } \\
\text { inibirão o acetato e a } \\
\text { produção de biogás }\end{array}$ \\
\hline $\begin{array}{c}\text { Acidez/Alcalinidade } \\
\text { (AV/AT) }\end{array}$ & 0,1 a 0,5 & $\begin{array}{l}\text { Representa estabilidade } \\
\text { para processos anaeróbios, } \\
\text { valores superiores } \\
\text { representam acúmulo de } \\
\text { ácidos nos reatores. }\end{array}$ \\
\hline $\mathrm{C} / \mathrm{N}$ & 20 a 30 & $\begin{array}{l}\text { Relação mais elevadas } \\
\text { levam ao consumo de N } \\
\text { pelas metanogênicas, } \\
\text { reduzindo a produção de } \\
\text { metano. }\end{array}$ \\
\hline $\begin{array}{l}\text { Carga orgânica } \\
\left(\mathrm{kgSV} \cdot \mathrm{m}^{3} \cdot \mathrm{r}^{-1} \cdot \mathrm{d}^{-1}\right) \\
\text { - Mesofílico } \\
\text { - Termofílico }\end{array}$ & $\begin{array}{l}0,4 \text { a } 6,4 \\
1,0 \text { a } 7,5\end{array}$ & $\begin{array}{l}\text { Os microrganismos se } \\
\text { inibem se a carga orgânica } \\
\text { for muito elevada. }\end{array}$ \\
\hline TRH (dias) & 9 a 95 & $\begin{array}{l}\text { Varia em função do } \\
\text { substrato, temperatura e o } \\
\text { tipo do sistema de digestão. }\end{array}$ \\
\hline
\end{tabular}

Fonte: Adaptado de Pecora (2006), Amani et al. (2010), Perovano \& Formigoni (2011) e Cabbai et al. (2013).

\section{Temperatura}

A temperatura é um dos parâmetros mais significativos de influência no processo de digestão anaeróbia, devido não somente à sua restrição na atividade enzimática e coenzimatica, mas também pela influência na produção de metano e na qualidade do digestato (APPELS et al., 2011). As bactérias podem crescer em temperaturas mínimas, ótimas e máximas, sendo que, na temperatura ótima, as enzimas encontram-se na forma mais ativa.

Em valores mínimos, a eficiência enzimática na taxa de conversão da matéria orgânica se reduz significativamente, limitando o processo de forma geral, ao passo que para a faixa máxima, pode ocorrer a desnaturalização das proteínas (destruição do arranjo molecular), acarretando na morte da célula (ALVES, 2008).

A temperatura influencia diretamente na etapa de hidrólise, onde caso ocorra redução na atividade enzimática, a velocidade global da reação do processo de degradação anaeróbia poderá ser limitada, dado que a hidrólise é a etapa inicial e responsável por tornar disponível o substrato para as demais etapas (CHERNICHARO, 2007). Lim \& Fox (2011) constataram redução na eficiência de remoção da DQO de 88,5 a $68,1 \%$ quando a temperatura foi reduzida de 24 a $16^{\circ} \mathrm{C}$, utilizando um reator com leito granular estático na estabilização de dejetos suínos.

Da mesma forma, as archeas metanogênicas são bastante sensíveis às variações de temperatura, e se desenvolvem principalmente em temperaturas mesofílicas $\left(30-40^{\circ} \mathrm{C}\right)$ e termofílicas $\left(40-70^{\circ} \mathrm{C}\right) .0$ arranjo termofílico apresenta maiores taxas de conversão dos sólidos em biogás, no entanto, o efluente é de baixa qualidade e o sistema é mais suscetível às instabilidades, que podem vir a inibir a produção do biogás. O processo mesofílico, apesar de possuir melhor estabilidade e maior diversidade microbiana, pode apresentar baixos teores de metano devido à maior demanda por nutrientes, devido à grande variedade de microrganismos operantes (MAO et al., 2015).

Para reatores operados abaixo de $30^{\circ} \mathrm{C}$ (temperaturas psicrofílicas), cada grau centígrado reduzido na temperatura implica em uma queda de $11 \%$ na taxa máxima do metabolismo anaeróbio, afetando a fração dos sólidos orgânicos que podem ser metabolizados, a taxa de transferência de gás e as características de sedimentação do lodo biológico (TCHOBANOGLOUS et al., 1993; VAN HAANDEL \& LETTINGA, 1994). Bouallagui et al. (2004) e Silva (2012) relatam que, em média, o crescimento microbiano ótimo se encontra por volta de 35 à $37^{\circ} \mathrm{C}$, 
promovendo a taxa máxima de produção de biogás.

\author{
Potencial hidrogeniônico, alcalinidade e ácidos graxos \\ voláteis
}

$\mathrm{O} \mathrm{pH}$ afeta diretamente o nível da atividade metabólica dos microrganismos metanogênicos a qual pode cessar em valores fora da faixa de 6,3 a 7,8. Ainda assim, na fase fermentativa onde ocorre a digestão ácida, a população microbiana tolera $\mathrm{pH}$ em níveis mais ácidos ou alcalinos. No entanto, o pH abaixo de 4,5 detém a atividade de todos os microrganismos implicados no processo. $\mathrm{O} \mathrm{pH}$ influencia não somente na produção do biogás como também na sua qualidade, em que, valores abaixo de seis resultam em um biogás pobre em metano (LEMA \& MÉNDEZ, 1997).

Os ácidos em concentrações acima da capacidade digestora da população microbiana específica para a sua degradação, colocam em risco a estabilidade da fermentação. A principal causa é o desbalanceamento entre a produção de ácidos e de bicarbonatos na primeira etapa da digestão, onde a alcalinidade proporcionada pelos bicarbonatos não é suficiente para neutralizar os ácidos, ocasionando uma queda no $\mathrm{pH}$, prevalecendo a fermentação ácida (PAES, 2003).

Isso ocorre devido à escala logarítmica do $\mathrm{pH}$, onde pequenos decréscimos no $\mathrm{pH}$ envolvem um elevado consumo de alcalinidade, reduzindo a solução tampão do meio. Da mesma forma, se o meio estiver alcalino $(\mathrm{pH}>8)$, diminui-se a eficiência do sistema, uma vez que pode influenciar a produção de amônia, componente tóxico para o processo anaeróbio em concentrações acima de 150 mg. L $^{-1}$ (CHERNICHARO, 2007).

Os ácidos graxos voláteis (AGV) e a alcalinidade são importantes indicadores da estabilidade em reatores anaeróbios. A acidez volátil, quantificada em $\mathrm{mg}$ de ácido acético por $L$, indica a concentração de ácidos e mede a capacidade do processo fermentativo anaeróbio em resistir à elevação do $\mathrm{pH}$ quando uma base é adicionada. $\mathrm{A}$ alcalinidade total, quantificada em $\mathrm{mg}$ de carbonato de cálcio por $\mathrm{L}$, indica a concentração de álcalis participantes na fermentação e mede a capacidade do sistema em resistir ao abaixamento do $\mathrm{pH}$ quando da adição de ácidos. Os dois indicadores são os mais importantes para o monitoramento de processos anaeróbios (AMANI et al., 2010).

Portanto, é necessário dosar a quantidade de substrato a ser adicionada ao reator, na qual a referência estimativa é a relação de ácidos voláteis $x$ alcalinidade (AV/AT) existente na fermentação, cujo valor conforme Sánchez et al. (2005), deve ser entre 0,1 a 0,5 para que o sistema mantenha o equilíbrio nas reações de produção e de consumo dos compostos.

\section{Características da biomassa e carga orgânica}

O teor de matéria rapidamente biodegradável, como carboidratos, proteínas e lipídios, relaciona-se com o desenvolvimento dos microrganismos, portanto, afeta qualitativamente e quantitativamente a produção do biogás (MACIEL \& JUCÁ, 2011).

Segundo Tchonobaglous et al. (1993), os resíduos alimentares se enquadram na categoria de resíduos rapidamente biodegradáveis. Zhang et al. (2014) mencionam que a concentração de sólidos voláteis (SV) de determinado substrato também se refere ao seu teor de matéria orgânica biodegradável. Outros autores indicam o parâmetro Carbono Orgânico Total (COT) para avaliar o teor de matéria orgânica dos substratos (GRIGATTI et al., 2004; FONSECA et al., 2006). Ainda assim, o parâmetro mais utilizado para esse fim é a caracterização dos sólidos, devido principalmente ao baixo custo e a menor onerosidade do ensaio (HAMILTON, 2012).

A Tabela 2 apresenta os dados obtidos por diferentes autores sobre a caracterização do teor de sólidos dos resíduos alimentares.

Tabela 2. Teor dos sólidos de resíduos alimentares

\begin{tabular}{cccc}
\hline Parâmetro & $\begin{array}{c}\text { Zhang et al. } \\
\text { (2007) }\end{array}$ & $\begin{array}{c}\text { Li et al. } \\
\mathbf{( 2 0 1 0 )}\end{array}$ & $\begin{array}{c}\text { Haider et al. } \\
\text { (2015) }\end{array}$ \\
\hline $\mathrm{ST}^{1}$ (\% b.s.) & $30,90+-0,07$ & 24,00 & 24,00 \\
$\mathrm{SV}^{2}$ (\% b.s.) & $26,35+-0,14$ & 23,20 & 22,13 \\
$\mathrm{STV}^{3}$ (\%) & $85,30+-0,65$ & 94,10 & 92,20 \\
\hline
\end{tabular}

'Sólidos totais; ${ }^{2}$ Sólidos voláteis; e ${ }^{3}$ Sólidos totais voláteis

Angelidaki et al. (2009) relatam que materiais com teores de STV acima de $80 \%$ apresentam excelentes perfis de biodegradabilidade e podem ser utilizados em sistemas anaeróbios. Foster-Carneiro et al. (2008) mostram que reatores operando com um teor de sólidos totais (ST) entre 20 a 30\%, atingem produção de biogás mais efetiva e mais rica em metano, devido à presença da umidade que permite maior absorção dos nutrientes por parte dos microrganismos atuantes. Além disso, a umidade é fundamental para assegurar a eficiência dos processos metabólicos, a mobilização e o crescimento microbiano (SILVA, 2012).

A carga orgânica é representada pela quantidade de sólidos voláteis inseridos ao reator. Com o aumento da carga orgânica a produção de biogás tende a ampliar, respeitando-se o limite máximo de $6,4 \mathrm{~kg} \cdot \mathrm{m}^{-3} \cdot \mathrm{d}^{-1}$, caso 
contrário, o equilíbrio do processo de digestão pode ser gravemente afetado com inibição microbiana. Alterações repentinas no tipo de substrato a ser inserido ao reator também podem levar a inibição da atividade microbiana nas fases da fermentação (MAO et al., 2015). Portanto, é fundamental que o dimensionamento do reator seja adequado aos parâmetros de entrada, como o tipo de substrato e a carga orgânica diária de alimentação.

\section{Nutrientes e Relação C/N}

A presença de macro e micronutrientes é fundamental para o metabolismo, crescimento e atividade bacteriana. Os principais nutrientes para a vida dos microrganismos anaeróbios são o carbono, nitrogênio e o fósforo, bem como uma série de elementos minerais como enxofre, ferro, potássio, sódio, cálcio e magnésio, fornecidos principalmente pela hidrólise dos carboidratos, das proteínas e dos lipídios (PARK, 2012). Tais nutrientes, em níveis balanceados, influenciam positivamente $\mathrm{O}$ desenvolvimento dos microrganismos e, consequentemente, o processo de digestão e de produção de biogás.

A relação $\mathrm{C} / \mathrm{N}$ é um índice significativo da capacidade de digestão e do rendimento potencial da biomassa, onde seu valor varia em função da biomassa. Uma relação adequada para o desenvolvimento dos microrganismos está contida na faixa de 20 a 30 (VERNA, 2002). O carbono é a principal fonte de alimentação dos microrganismos e componente principal do biogás. É derivado principalmente de hidratos de carbono contidos na biomassa, enquanto o nitrogênio é responsável pela síntese das proteínas dos organismos.

Em condições de excesso de nitrogênio (baixa relação $\mathrm{C} / \mathrm{N}$ ), ocorre acúmulo no meio, geralmente na forma de $\mathrm{NH}_{3}$, o que provoca uma inibição no crescimento das metanogênicas. Por outro lado, em condições de limitação da disponibilidade de nitrogênio (elevada relação $C / N$ ), os microrganismos não conseguem metabolizar o carbono presente, o que leva a uma ineficiência do processo (SGORLON et al., 2011). De forma geral, a ausência de nutrientes na mistura reduz o crescimento dos microrganismos metanogênicos, levando a intensa acumulação de ácidos orgânicos nos reatores anaeróbios, reduzindo assim a qualidade do biogás.

Os resíduos alimentares apresentam ótima biodegradabilidade, no entanto, carecem de nutrientes e sais minerais essenciais para o desenvolvimento dos microrganismos. Inibições podem ocorrer ao se digerir unicamente os resíduos alimentares por longos períodos de operação. As razões para a inibição são o desbalanceamento de nutrientes na fermentação, isto é, os elementos traço (zinco, ferro, molibdênio, entre outros) são insuficientes, os macronutrientes (sódio, potássio, entre outros) encontram-se em excesso (EL-MASHAD \& ZHANG, 2010; ZHANG et al., 2011; ZHANG et al., 2013). Devido a isso, diversos autores indicam o uso de dois ou mais substratos no processo para aproveitar a sinergia das mesclas, compensando as carências nutricionais dos substratos e suportar o crescimento dos microrganismos, consequentemente, melhorando a qualidade do biogás (ZHANG et al., 2014; RATANATAMSKUL et al., 2015; CHEN et al., 2016).

Atualmente, grande parte dos estudos encontrados na literatura sobre a digestão anaeróbia de resíduos alimentares relatam sobre a codigestão com diferentes substratos, por exemplo: resíduos alimentares com esterco bovino (BOULLAGUI et al., 2004; EL-MASHAD e ZHANG, 2010), resíduos alimentares com casca de arroz (HAIDER et al., 2015) e resíduos alimentares com palha (YONG et al., 2015). Dessa forma, é possível balancear os nutrientes do meio, proporcionando maiores taxas de produção de biogás.

\section{Agitação da biomassa}

A agitação da biomassa em um biodigestor anaeróbio tem um efeito significativo, pois promove a homogeneização do substrato e aumenta a cinética da velocidade de digestão anaeróbia, acelerando o processo de conversão biológica. Isso se deve ao aquecimento uniforme do substrato no interior do digestor bem como a maior facilidade de transferência de matéria, uma vez que as moléculas do substrato devem ser absorvidas pela superfície dos microrganismos e os produtos intermediários e finais devem ser transportados (TCHOBANOGLOUS et al., 1993). Além disso, a agitação previne a ocorrência de curtos circuitos (área mortas) no interior do biodigestor, promovendo com que todas as parcelas do substrato entrem em contato com os microrganismos.

Recomenda-se que apenas reatores com volume menor que $50 \mathrm{~m}^{3}$ operem sem agitadores; visto que, para os reatores de maior porte é fundamental que haja agitação durante o processo de digestão (DEUBLEIN \& STEINHAUSER, 2008). A agitação pode ser realizada de diversas maneiras, por dispositivo mecânico, recirculação do conteúdo do biodigestor ou recirculação do próprio biogás gerado. Vale ressaltar que a intensidade e a duração da agitação são cruciais para o procedimento (KARIM et al., 
2005).

\section{Substâncias toxicas e inibição}

Existe uma grande variedade de substâncias tóxicas responsáveis pela falha de sistemas anaeróbios. $\mathrm{O}$ acúmulo dos ácidos orgânicos produzidos no primeiro estágio do processo é um dos principais causadores de instabilidades no processo de digestão anaeróbia, assim como variações bruscas dos fatores ambientais também podem interferir no processo, tais como no $\mathrm{pH}$, temperatura, nutrientes, carga orgânica e a presença de agentes inibitórios em reatores anaeróbios, que incluem elevadas concentrações de amônia, sulfatos e de metais pesados, principalmente (CHEN et al., 2016).

De maneira geral, os compostos tóxicos podem ter diferentes efeitos sobre a biota de sistemas anaeróbios, podendo ter um efeito bactericida quando as bactérias não suportam a presença do contaminante, ou bacteriostático quando as bactérias conseguem se adaptar sob determinadas concentrações do contaminante tóxico e, portanto, resistindo e recuperando-se à atividade normal após um determinado tempo resiliência (AMANI et al., 2010).

Sobretudo, a melhor forma de combater agentes tóxicos é com o uso de um agente antagônico, onde um produto tóxico é anulado na presença de outro. A exemplo, o Sódio ( $\mathrm{Na}$ ) e o Potássio (K) em mistura se anulam, diminuindo o efeito tóxico de ambos. Dentre os principais agentes inibitórios, têm-se os nitratos, cianetos, fenóis, sódio, potássio, cálcio, magnésio, nitrogênio amoniacal, oxigênio e metais pesados apenas quando solúveis. Contudo, a toxicidade destes componentes varia em função de sua concentração no meio (FORESTI, 1993).

\section{Partida de reatores anaeróbios}

A partida de reatores anaeróbios ou repartida após manutenções é, geralmente, a etapa mais crítica para o sucesso do processo, visto que é responsável pelo início de toda atividade microbiana. Essa etapa depende de vários fatores, como a fonte de microrganismos (inoculo) a ser utilizada e o modo de operação inicial, por exemplo (LOPES et al., 2004). É fundamental que o inoculo apresente uma comunidade de microrganismos facultativos e metanogênicos para garantir o desempenho inicial do processo de digestão anaeróbia (AMANI et al., 2010).

Considera-se que a partida de sistemas anaeróbios é uma área que ainda necessita de pesquisa intensiva. Amani et al. (2010) sugerem, entretanto, a avaliação em conjunto com outros critérios, como diferentes formas de prétratamento da biomassa a fim de se investigar tecnicamente o real desempenho da partida de reatores anaeróbios.

Silva (2014) investigou os efeitos do uso de lodo anaeróbio e dejetos bovinos para a partida de um reator para tratar resíduos alimentares, apontando o lodo anaeróbio proveniente de um reator UASB de estação de tratamento de esgoto com maior índice de aclimatação de inoculo sobre o substrato, podendo verificar uma produção de metano crescente já nos primeiros dias. Ressalta ainda, que para melhores resultados, utilizar um inoculo da mesma natureza do substrato, permite que a fase de aclimatação seja mais ágil, além de proporcionar melhores condições para o desenvolvimento microbiano. No entanto, ainda há muitas controvérsias sobre qual o melhor inoculo para aclimatar determinado substrato, bem como a proporção ótima entre eles.

\section{CONCLUSÕES}

A digestão anaeróbia de resíduos alimentares é um processo complexo que deve simultaneamente digerir carboidratos, proteínas e gorduras em um sistema de simples estágio. Considerando que o processo é influenciado estreitamente por diversos parâmetros chave, como temperatura, $\mathrm{pH}$, concentração de AGV, de amônia, de nutrientes, entre outros, é importante mantêlos em níveis apropriados por longos tempos de operação, para assim obter maior eficiência e rentabilidade no processo.

\section{REFERÊNCIAS}

ABRELPE - Associação Brasileira de Empresas de Limpezas Públicas e Resíduos Especiais. Panorama dos resíduos sólidos no Brasil. São Paulo, 2013.

ABRELPE - Associação Brasileira de Empresas de Limpezas Públicas e Resíduos Especiais. Panorama dos resíduos sólidos no Brasil. São Paulo, 2014.

ALVES, I. R. F. S. Análise experimental do potencial de geração de biogás em resíduos sólidos urbanos. 2008. 134 f. Dissertação (Mestre em Engenharia Civil) - Universidade Federal de Pernambuco, Recife, 2008.

AMANI, T.; NOSRATI, M.; SREEKRISHNAN, T. R. Anaerobic digestion from the viewpoint of microbiological, chemical, and operational aspects - a review. Environmental Reviews, n. 18, p. 255-278, 2010

ANGELIDAKI, I.; ALVES, M.; BOLZONELLA, D.; BORZACCONI, L.; CAMPOS, J. L.; GUWY, A. J.; KALYUZHNYI, S.; JENICEK, P.; VAN LIER, J. B. Defining the biomethane potential (BMP) of solid 
organic wastes and energy crops: a proposed protocol for batch assays. Water Science \& Technology, v. 59. n. 5, p. 927-934, 2009.

APPELS, L.; ASSCHEB, A. V.; WILLEMSB, K.; DEGRÈVEA, J.; IMPEA, J. V.; DEWIL, R. Peracetic acid oxidation as an alternative pretreatment for the anaerobic digestion of waste activated sludge. Bioresource Technology, v. 102, n. 5, p. 4124-4130, 2011.

BAZARA, X.; GALIMANY, F.; TORRES, R. Digestión anaerobia en el tratamiento de efluentes y lodos residuales. Tecnología del Agua, n. 233, p. 34-46, 2003.

BOUALLAGUI, H.; HAOUARI, O.; TOUHAMI, Y.; CHEICKH, R. B.; MAROUANI, L.; HAMDI, M. Effect of temperature on the performance of an anaerobic tubular reactor treating fruit and vegetable waste. Process Biochemistry, v. 39, p. 2143-2148, 2004.

CABBAI, V.; BALLICO, M.; ANEGGI, E.; GOI, D. BMP tests of source selected OFMSW to evaluate anaerobic codigestion with sewage sludge. Waste management, v. 33, n. 7, p. 1626-1632, 2013.

CHEN, G.; LIU, G.; YAN, B.; SHAN, R.; WANG, J.; LI, T.; WU, W. Experimental study of co-digestion of food waste and tall fescue for biogas production. Renewable Energy, v. 88, p. 273-279, 2016.

CHERNICHARO, C. A. L. Reatores anaeróbios. Belo Horizonte: Departamento de Engenharia Sanitária e Ambiental - UFMG, v. 5, n. 2, 2007. 380 p.

DEUBLEIN, D.; STEINHAUSER, A. Biogas from waste and renewable resources: an introduction. Weinheim: Wiley- $\mathrm{VCH}$ Verlag Gmbh \& Co. KGaA, 2008.

EL-MASHAD, H. M.; ZHANG, R. Biogas production from codigestion of dairy manure and food waste. Bioresource Technology, v. 101, p. 4021-4028, 2010.

FONSECA, J. C. L.; SILVA, M. R. A.; BAUTITZ, I. R.; NOGUEIRA, R.F. P.; MARCHI, M. R. R. Avaliação da confiabilidade analítica das determinações de carbono orgânico total (COT). Eclética Química, v. 31, n. 3, p. 47, 52, 2006.

FORESTI, E. Notas da aula de Processos e Operações em Tratamento de Resíduos SHS-705. São: Carlos: Pós-Graduação em Hidráulica e Saneamento da Escola de Engenharia de São Carlos, 1993.

FOSTER-CARNEIRO, T; PÉREZ, M; ROMERO, L. I. Influence of total solid and inoculum contents on performance of anaerobic reactor treating food waste. Bioresource Technology, v. 99, p. 6994$7002,2008$.

GRIGATTI, M.; CIAVATTA, C.; GESSA, C. Evolution of organic matter from sewage sludge and garden trimming during composting. Bioresource Technology, v. 91 n. 2, p. 163-169, 2004.

HAMILTON, D. W. Anaerobic digestion of animal manures: methane production potential of wastes materials. Oklahoma State University: Division of Agricultural Sciences and Natural Resources: BAE-1762, 2012.
HAIDER, M. R.; ZESHAN; YOUSAF, S.; MALIK, R. N.; VISVANATHAN, C. Effect of mixing ratio of food waste and hice husk co-digestion and substrate to inoculum ration on biogas production. Bioresource Technology, v. 190, p. 451-457, 2015.

KARIM, K.; HOFFMANN, R.; KLASSON, T.; AL-DAHHAN, M. H. Anaerobic digestion of animal waste: Waste strength versus impact of mixing. Bioresource Technology, v. 96, p. 1771-1781, 2005.

LEMA, J. M.; MÉNDEZ, R. J.; Tratamientos biológicos anaerobios. In: BUENO, J.; SASTRE, L.; LAVIN, A. (eds) Contaminación e ingeniéria ambiental, v. 3. Contaminación de las aguas. F.I.C.Y.T, Oviedo, 1997.

LI, R. P.; WANG, K. S.; Li, X. J.; PANG, Y. Z. Characteristic and anaerobic digestion performances of kitchen wastes. Renewable Energy, v. 28, p. 76-80, 2010.

LIM, S. J.; FOX, P. A kinetic evaluation of anaerobic treatment of swine wastewater at two temperatures in a temperate climate zone. Bioresource Technology, v. 102, n.4, p.3724-3729, 2011.

LOPES, W. S.; LEITE, V. D.; PRASAD, S. Influence of inoculum on performance of anaerobic reactors for treating municipal solid waste. Bioresource Technology, v. 94, n. 3, p. 261-266, 2004.

MACIEL, F. J.; JUCÁ, J. F. T. Evaluation of landfill gas production and emissions in a MSW large-scale experimental cell in Brazil. Waste Management, v. 31, n. 5, p. 966-977, 2011.

MAO, C.; FENG, Y.; WANG, X.; REN, G. Review on research achievements of biogas from anaerobic digestion. Renewable and Sustainable Energy Reviews, v. 45, p. 540-555, 2015.

OLIVEIRA, M. M. Estudo da inclusão de compartimentos em reatores modelo canadense. 2012. 119 f. Dissertação (Mestrado) - Universidade Federal de Santa Maria, Santa Maria, 2012.

PAES, R. F. C. Caracterização do chorume produzido no aterro da Muribeca - PE. 2003. 150 f. Dissertação (Mestrado) Universidade Federal de Campina Grande, Campina Grande, 2003.

PARK, S.; LI, Y. Evaluation of methane production and macronutrient degradation in the anaerobic co-digestion of algae biomass residue and lipid waste. Bioresource technology, v. 111, p. 42-48, 2012.

PECORA, V. Implantação de uma unidade demonstrativa de geração de energia elétrica a partir do biogás de tratamento do esgoto residencial da USP - Estudo de caso. 2006. $152 \mathrm{f}$. Dissertação (Mestrado em Energia) - Universidade de São Paulo, São Paulo, 2006.

PEROVANO, T. G; FORMIGONI, L. P. A. Geração de energia a partir de subprodutos do tratamento de esgotos sanitários. 2011. 101 f. Monografia (Graduação em Engenharia Ambiental) Universidade do Espirito Santo, Vitória. 2011.

PITK, P.; KAPARAJU, P.; PALATSI, J; AFFES, R.; VILU, R. Co-digestion of sewage sludge and sterilized solid slaugherhouse waste: Methane production efficiency and process limitations. Bioresource Technology, v. 134, p. 227-232, 2013. 
RATANATAMSKUL, C.; WATTANAYOMMANAPORN, O.; YAMAMOTO, K. An on-site prototype two-stage anaerobic digestor for co-digester of food waste and sewage sludge for biogas production from high-rise building. International Biodeterioration \& Biodegradation, v. 102, p. 143-148, 2015.

SÁNCHEZ, E.; BORJA, R.; TRAVIESO, L.; MARTÍN, A.; COLMENAREJO, M.F. Effect of organic loading rate on the stability, operational parameters and performance of a secondary up flow anaerobic sludge bed reactor treating piggery waste. Bioresource Technology, v. 96, n. 3, p. 335-344, 2005.

SANTOS, A. T. L.; HENRIQUE, N. S.; SHHILINDWEIN, J. A.; FERREIRA, E.; STACHIW, R. Aproveitamento da fração orgânica dos resíduos sólidos urbanos para produção de composto orgânico. Revista Brasileira de Ciências da Amazônia, v. 3, n. 1, p. 15-28, 2014.

SILVA, G. A. Estimativa da geração de biogás no aterro sanitário metropolitano de João Pessoa através do teste BMP. 2012. 128 f. Dissertação (Mestrado em Engenharia Urbana e Ambiental) Universidade Federal da Paraíba, 2012.

SILVA, M. C. P. Avaliação de lodo anaeróbio e dejeto bovino como potencial inoculos para partida de digestores anaeróbios de resíduos alimentares. 2014. 115 f. Dissertação (Mestrado) Universidade Federal de Minas Gerais, Belo Horizonte, 2014.

SGORLON, J. G.; RIZK, M. C.; BERGAMASCO, R.; TAVARES, C. R. G. Avaliação da $\mathrm{DQO}$ e da relação $\mathrm{C} / \mathrm{N}$ obtidas no tratamento anaeróbio de resíduos fruti-hortículas. Acta Scientiarum Technology, v. 33, n. 4, p. 421-421, 2011.

TCHOBANOGLOUS, G.; THEISEN, H.; VIGIL, S. Integrated solid waste management: engineering principles and management issues. New York: Mcgraw-Hill, 1993. 978 p.

VAN HAANDEL, A. C.; LETTINGA, G. Tratamento anaeróbio de esgotos: um manual para regiões de clima quente. São Paulo, SP: Mc. Graw Hill, 1994. 199 p.

VERNA, S. Anaerobic digestion of biodegradable organics in municipal solid wastes. 2002. 50 f. Dissertação (Master in Earth Resources Engineering) - Columbia University, New York, 2002.

WOON, K. S.; LO, I. M. C. A proposed framework of food waste collection and recycling for renewable biogas fuel production in Honk Kong. Waste Management, v. 47, p. 3-10, 2016.

XU, C.; SHI, W.; HONG, J.; ZHANG, F.; CHEN, W. Life cycle assessment of food waste-based biogas generation. Renewable and Sustainable Energy Reviews, v. 49, p. 169-177, 2015.

YONG, Z.; DONG, Y.; ZHANG, X.; TAN, T. Anaerobic co-digestion of food waste and straw for biogas production. Renewable Energy, v. 78, p. 527-530, 2015.

ZANDONADI, H. S.; MAURÍCIO, A. A. Avaliação do índice de restoingesta, de refeições consumidas por trabalhadores da construção civil no município de Cuiabá, MT. Revista Higiene Alimentar, v. 26, n. 206/207, p. 64-70, 2012.

ZHANG, C.; SU, H.; BAEYENS, J.; TAN, T. Reviewing the anaerobic digestion of food waste for biogas production. Renewable and
Sustainable Energy Reviews, v. 38, p. 383-392, 2014.

ZHANG, C.; SU, H.; TAN, T. Batch and semi-continuous anaerobic digestion of food waste in a dual solid-liquid system. Bioresource Technology, v. 145, p. 10-13, 2013.

ZHANG, L.; LEEB, Y-W.; JAHNGA, D. Anaerobic co-digestion of food waste and piggery wastewater: Focusing on the role of trace elements. Bioresource Technology, v. 102, n. 8, p. 5048-5059, 2011.

ZHANG, R.; EL-MASHAD, H. M.; HARTMAN, K.; WANG, F.; LIU, G.; CHOATE, C.; GAMBLE, P. Characterization of food waste as feedstock for anaerobic digestion. Bioresource Technology, v. 98, p. 929-935, 2007. 